\title{
Saberes populares e cientificismo na estratégia saúde da família: complementares ou excludentes?
}

\author{
Popular wisdom and scientifism in "family health" strategy: \\ complementarity ou exclusion?
}

José Roque Junges ${ }^{1}$

Rosangela Barbiani ${ }^{2}$

Natália de Ávila Soares ${ }^{2}$

Raquel Brondísia Panizzi Fernandes ${ }^{2}$

Marília Schreck de Lima ${ }^{2}$

\footnotetext{
${ }^{1}$ Programa de Pós-

Graduação em Saúde

Coletiva, Universidade do

Vale do Rio dos Sinos

(UNSINOS). Caixa Postal

101. 93.001-970 São

Leopoldo RS.

jrjunges@unisinos.br

${ }^{2}$ Bolsistas de Iniciação

Científica e alunas dos

cursos de Fisioterapia e

Psicologia da UNISINOS
}

\begin{abstract}
The "Family Health" Strategy has been created to replace the traditional model of healthcare. It assumes the integration of subjective and social dimensions of users, overcoming the reduction of the health/disease process to pure technical-scientific limits. The scope of this article is to understand how the health professionals deal with popular wisdom of the Family Health Strategy users. The methodology is explanatory with a qualitative approach, using the focal group as a technique for the collection of data, and content anal$y$ sis for interpretation of the results. The sample is formed by participants of the seven teams of the Family Health Strategy of the municipality of Campo Bom - State if Rio Grande do Sul, chosen according to criteria of competences, totaling twelve members. The results present divergences between professionals about accepting or not accepting popular wisdom. Many do not consider the subjectivity and the social representations of popular culture in the health/disease process. Others only tolerate this knowledge as a strategy to make the users accept the proposed therapy. However a minority values this knowledge as complementary to the scientific universe, in the construction of a comprehensive approach.
\end{abstract}

Key words Family health, Professionals, Culture, Health, Knowledge
Resumo A Estratégia Saúde da Família foi criada para superar o modelo tradicional de assistência em saúde. Ela pressupõe a integração das dimensões subjetivas e sociais dos usuários, ultrapassando a redução do processo saúde/doença a puros limites técnico-científicos. $O$ artigo tem por objetivo compreender como os profissionais da saúde lidam com os conhecimentos populares dos usuários da estratégia. A metodologia caracteriza-se como exploratória com abordagem qualitativa, a técnica para a coleta de dados foi grupo focal, e para interpretação dos resultados, a análise de conteúdo. Participam da amostra integrantes das sete equipes da Estratégia Saúde da Família do município de Campo Bom - RS, escolhidos segundo critérios de competência, somando doze membros. Os resultados mostraram divergências entre os profissionais sobre como acolher ou não saberes populares. Muitos não consideram a subjetividade e as representações sociais da cultura popular no processo saúde/doença. Outros toleram estes saberes como mecanismo para que o usuário aceite a terapia proposta. Apenas uma minoria valoriza esses conhecimentos, como complementares ao universo científico, na construção da integralidade.

Palavras-chave Saúde da família, Profissionais, Cultura, Saúde, Conhecimento. 


\section{Introdução}

A assistência à saúde sempre esteve tradicionalmente caracterizada pelo modelo biomédico, tendo como foco a doença e a cura, interpretadas com parâmetros biológicos, e como base a relação vertical entre médico e paciente, para a qual os determinantes psicossociais e culturais interessam pouco para o diagnóstico e a terapêutica. A Estratégia "Saúde da Família" (ESF) é uma política pública com o objetivo de mudar esse modelo de assistência. Ela pressupõe a consideração das dimensões subjetivas e sociais, tanto de profissionais quanto de usuários, nas relações que se estabelecem entre os dois ${ }^{1}$. Assim o cuidado, o acolhimento e o vínculo tornam-se características de uma atenção voltada para a integralidade, na tentativa de consolidar a corresponsabilização como condição de uma assistência resolutiva e de qualidade.

Nesta perspectiva, os trabalhadores de saúde atuam como dispositivos de mudanças, sendo necessário constituir uma nova ética, que reconheça os serviços de saúde como espaços públicos, onde o trabalho deve ser presidido por valores humanitários, de solidariedade e reconhecimento de direitos de cidadania ${ }^{1}$. Assim, os usuários tornam-se o núcleo da produção em saúde. Essa mudança requer escuta e acolhida dos saberes populares por parte dos profissionais, possibilitando 'trocas' de conhecimentos em vista de uma saúde integral, conforme Briceño-León ${ }^{2}$ os programas não podem ser impostos para a comunidade, mas é a comunidade que deve responsabilizar-se por sua própria saúde. Mas para isso é necessário que os profissionais estejam atentos aos usos e costumes culturais da comunidade atendida. Tendo presente que a cultura interfere diretamente nos processos de saúde e doença, as representações dos usuários sobre o modo de enfrentar esse processo são essenciais para as práticas de cuidado. Por isso é importante entender como os profissionais reagem frente ao aparecimento de saberes sobre saúde que não são validados pelo conhecimento científico.

Estudo realizado por pesquisadores da Universidade do Vale do Rio dos Sinos (UNISINOS) acerca da percepção dos profissionais da ESF do município de Campo Bom (RS) sobre os aspectos éticos da sua prática e aponta para divergências sobre como acolher ou não terapias alternativas. O artigo tem por objetivo compreender como os profissionais da ESF lidam com os conhecimentos populares sobre saúde e doença em confronto com o cientificismo da sua formação, identificando nas suas falas como reagem diante dos saberes e terapias populares.

\section{Metodologia}

Foram realizadas consultas com o Coordenador Estadual da ESF no Rio Grande do Sul e com a Coordenadora da Primeira Regional de Saúde para selecionar o município a ser estudado. Os critérios para seleção deste foram: 1) mais de três anos de implantação da ESF; 2) município de porte médio ( $>50$ mil habitantes) pertencente à região metropolitana de Porto Alegre; 3) cobertura do Programa abrangendo mais de $40 \%$ da população. O município escolhido foi Campo Bom, que implantou a ESF em 2001; contava, na época, com 55.310 habitantes e sua abrangência era de $43,66 \%$ da população (dados fornecidos pela Coordenadoria Regional da Saúde em 2004). Em seguida, entrou-se em contato com a Secretaria Municipal de Saúde e com o Coordenador Municipal da ESF para discutir sobre a viabilidade da pesquisa.

A pesquisa é exploratória com abordagem qualitativa. A coleta de dados foi pela técnica de discussão focal em grupo. Essa técnica é preferível quando se quer captar a percepção de um grupo organizado, no caso os profissionais da ESF, sobre determinado aspecto das suas atividades ou das suas relações de trabalho. As discussões foram gravadas e depois transcritas. A leitura reiterada dessas transcrições permitiu, por meio de análise de conteúdo proposta por Bar$\operatorname{din}^{3}$, chegar a núcleos temáticos que definiram os resultados da investigação.

A seleção dos participantes do grupo focal foi intencional a partir de visitas dos pesquisadores às sete equipes da ESF do município. $\mathrm{O}$ grupo pesquisado foi escolhido segundo critérios proporcionais de competências profissionais e de distribuição por equipe: três médicos, três enfermeiros, dois técnicos em enfermagem e quatro agentes comunitários de saúde, totalizando doze membros.

Para a coleta de dados foram realizadas oito reuniões do grupo, cada uma com aproximadamente uma hora e meia de duração, em sala cedida pela secretaria municipal de saúde, tendo como foco de discussão aspectos éticos de quatro temáticas: 1) a própria Estratégia Saúde da Família; 2) a prática dos profissionais; 3 ) as relações entre os profissionais e a comunidade e 4) a tradição cultural da comunidade. O artigo é um recorte, principalmente, dessa última temática, 
A atenção básica em saúde defendida pela ESF, baseada na participação da comunidade, permite incluir a lógica da determinação social no processo saúde/doença. Aponta para uma configuração diferente das ações em saúde por parte dos profissionais, convidados a repensarem suas práticas a partir de dinâmicas relacionais.

A ESF está inserida em uma comunidade e nas suas representações sociais, exigindo grande conhecimento de seu campo de atuação e de suas possibilidades de interação. Neste contexto, somam-se diversos conhecimentos, superando limitações ideológicas. Nos grupos focais analisados constataram-se divergências sobre como lidar e acolher ou não os saberes populares e as terapias alternativas utilizadas pelos usuários. Foram encontrados três tipos de visões: a sobreposição de um saber sobre o outro, a tolerância do saber científico em relação ao popular e a integração entre ambos os saberes.

\section{Sobreposição de saberes}

A análise aponta para uma sobreposição de conhecimentos com formas distintas de manifestação. Por um lado nota-se a valorização dos saberes populares em detrimento dos científicos; de outro, a sobreposição de saberes científicos sobre os populares.

Essa sobreposição aparece na constatação de uma técnica em enfermagem: O médico tem uma concorrente forte: uma benzedeira... Impressionante como no dia-a-dia as pessoas ainda deixam o tratamento e procuram uma benzedeira, acreditam muito mais do que nas tecnologias atuais.

A sobreposição de saberes populares é constatada quando o usuário não realiza o tratamento considerado como 'convencional' e adequado pelo profissional. Em contrapartida, utiliza tratamentos alternativos por se aproximarem de suas necessidades específicas e por fazerem parte de seu universo.

A sobreposição de saberes científicos é identificada quando os profissionais não compreendem o quanto estas representações socioculturais são sugestivas para a população. Desta for- ma, acabam por não entender o porquê da resistência na adequação a um tratamento convencional e a 'troca' deste por outro de maior significado para o usuário ${ }^{4,5}$.

Ao optar por uma curandeira popular, o usuário estaria optando por uma explicação mais inteligível do que é saúde, qual a causa da doença e qual o tratamento necessário e condizente com a sua compreensão de tratamento. A cultura popular oferece um modo de entender o corpo e o seu funcionamento, conhecimento que é utilizado para organizar as informações disponíveis com coerência ${ }^{6}$.

A força da visão popular sobre a doença está expressa no relato de uma enfermeira: Entre escutar o que o enfermeiro e o médico falam, ela acha que é mais importante escutar, de repente, a mãe dela. Conta mais a orientação da mãe, do que a do profissional. A mesma constatação aparece na fala de uma técnica: [...] Ontem uma menina ganhou bebê e estava com muita cólica. Disse que iria fazer um chá de manjerona... Que a mãe dela ensinou, eles sempre fizeram e nunca fez mal para as crianças. Então não se pode dizer 'não faz', porque eles tão acostumados com aquilo...

Para entender esta visão popular é importante trazer a compreensão de Moscovici ${ }^{7}$ sobre as representações sociais, quando reporta a construção do universo consensual e reificado. Esses dois conceitos ajudam a entender como interfere e como interage o saber popular e o conhecimento científico. O universo consensual identifica-se com o senso comum transformado continuamente pelas experiências do grupo de pessoas, tidas como iguais e livres, que comungam dessa visão permeada de significados e interpretações. A cultura é o lócus onde se articulam os conflitos e as concessões, as tradições e as mudanças e onde tudo ganha sentido ${ }^{8}$. Ela fornece os elementos para que os eventos, as práticas do cotidiano, inclusive as relativas à saúde, sejam compreendidas e aceitas ${ }^{7}$.

Essa diferença aparece na seguinte fala de uma enfermeira: É o meio em que a pessoa vive, para eles aquilo não é errado, para nós é... Então até perceberem que aquilo está prejudicando a eles e não a nós, eles entendem isso como uma ofensa... 'Eu não consigo abrir a minha mente', então pra mim aquilo é normal...

$\mathrm{O}$ universo reificado refere-se à visão científica restrita ao grupo de iniciados que têm competência adquirida para interferir e produzir ciência, onde a especialidade determina quem pode intervir sobre o assunto. Cria um sistema social de papéis e classes de acordo com o mérito e o 
reconhecimento entre os pares, indiferente à individualidade e identidade dos membros da sociedade tidos como desiguais ${ }^{7}$.

Muitos profissionais entendem que a solução para todos os males está na medicalização e no saber comprovado cientificamente. Ao legitimarem terapêuticas científicas, outorgam às práticas resultantes da medicina convencional a única possibilidade de êxito na saúde do usuário. Julgam seus saberes como soberanos e nem cogitam outra possibilidade de tratamento, despersonalizando o indivíduo. O processo de medicalização tem na medicina científica o seu fio condutor e indutor, ignorando a individualidade do paciente face ao seu caráter curativo, ou mesmo preventivo, através da ênfase na doença9 ${ }^{9}$.

Isso aparece na fala de uma enfermeira: $\grave{s}$ vezes o cuidado frustra a gente, por exemplo: acompanha uma gestante por todo o pré-natal. Orienta, ensina tudo e ela entende. [...] Tu fez o serviço 100\%... E daqui um pouco tu vê: caiu tudo por terra, porque o bebê nasce e aquilo tudo que foi ensinado, parece que ela não aprendeu!

Choques entre culturas, de profissionais e usuários, são fenômenos usuais na assistência à saúde, já que a consulta requer troca de informações. Embora os profissionais encontrem contribuições no conhecimento popular, não estão preparados para lidar com o mesmo, sentindose pouco reconhecidos e valorizados, quando, na verdade, a não adesão do usuário ao procedimento explica-se porque o que é proposto não faz sentido ao seu universo de representações.

Esse estranhamento do profissional aparece na fala de uma enfermeira: Encontrei uma gestante que estava, há não sei quanto tempo, sem lavar o cabelo porque a mãe dizia que não podia até 40 dias... E nem o bebê... Ela também não o molhou até cair o umbigo, sabe, tradição antiga!.

A compreensão das representações etiológicas e das formulações de juízos de diagnóstico sobre as doenças e o próprio quadro global da visão de saúde não estão separados dos mapas cognitivos e do patrimônio cultural das populações ${ }^{10}$. O resgate da historicidade dos usuários baseado em relações de respeito, distanciandose de práticas que consideram a sua visão como obsoleta, pode representar uma importante ferramenta para melhor adesão ao tratamento ${ }^{5}$.

Esse distanciamento é corroborado pela fala da enfermeira: Nós tivemos que ir à casa de uma menina que a avó do marido é que estava cuidando e não deixava dar banho no bebê. Era só paninho, até cair o umbigo. Então a enfermeira pegou e botou dentro d'água. A avó quase teve um troço!
Os profissionais imersos numa sociedade normatizadora, tendente a desqualificar valores e práticas do saber não científico, desconsideram os saberes populares. O usuário, confiscado da possibilidade de se manifestar em sua singularidade, é tido pela ciência como um indivíduo numérico a mais, respondendo a uma categorização de diagnóstico e a uma uniformização de terapêutica. Passivo e distante de sua raiz cultural, o sujeito é impedido da necessária ancoragem para a significação do que lhe é proposto, suas percepções e representações individuais são excluídas do processo pessoal de saúde/doença.

Essa constatação é expressa pelo médico: $A$ questão cultural de ir até a unidade, primeiro eles fazem a tentativa de tudo resolver em casa, 'áh, porque eu achei que isso iria resolver, porque lá no interior eu fazia assim. Primeiro eu tomei um chá de boldo, tomei um chazinho de macela, porque antigamente a gente tomava isso e melhorava.

Aí eles falam: 'toma o chá tal que é bom pra tal coisa'. Parece que botou o teu trabalho por água abaixo. Mas é uma necessidade de uma autogerência de algumas coisas [...].

Para Briceño-León ${ }^{2}$, as crenças populares são de extrema importância porque a realidade identifica-se com aquilo que se crê e não necessariamente coincide com o que cientificamente é pensado como tal. O real é construído no contexto cultural do ser humano. As práticas de saúde, fortemente ligadas à tecnologia e condicionadas pelo poder econômico, desviaram-se da sua referência fundamental que é a percepção do ser humano como um todo, cujas necessidades e respostas em matéria de saúde não podem ser classificadas segundo padrões universais, mas percebidas no interior de um enquadramento cultural específico ${ }^{10}$.

\section{Tolerância com os saberes populares}

Os profissionais que não sobrepõem o seu saber científico ao saber popular, por entenderem que essa prática não atende às necessidades do usuário, adotam como estratégia de intervenção a tolerância em relação aos conhecimentos trazidos por este. A tolerância é vista como uma forma de engajar a pessoa no tratamento proposto, contudo essas representações do usuário não fazem sentido para estes profissionais.

Essa tolerância aparece nas palavras do médico: [...] Ótimo tomar jambolão, mas toma o remedinho também, as duas coisas ajudam. A gente tem que convencê-los, não tentar muda-los, senão eles vão embora [...] Aí entra o nosso jogo de cintura de convencer, mas eu acho que tem que respei- 
tar essa crença popular [...]. A gente está conseguindo convencer e fazer um tratamento mais efetivo, a pessoa sai satisfeita, volta depois, passa a confiar em ti, tu acreditou nela.

Muitos profissionais não conseguem chegar a uma transferência efetiva entre os conhecimentos. No entanto, têm consciência de que sem a valorização do saber popular não há adesão ao tratamento.

Essa situação homogeneiza a saúde, desconsiderando a subjetividade. Existem lógicas que predominam no contexto sociocultural, determinando regimes de verdade que adquirem legitimidade social e desenvolvem processos tendentes a seguir as regras vigentes. Tolerar ou não o saber popular não depende de ações livres dos profissionais, mas da influência do modelo biomédico que preconiza o consumo de medicamentos e a consequente lógica do mercado ${ }^{11}$.

A força do modelo aparece na própria fala do agente: Para nós como agente de saúde eles falam bastante, a gente sempre procura dizer: 'tu não deixa de tomar os dois, mas toma o chá'. Tem um senhor que toma chá de lima e diz que para a pressão é ótimo, mas ele toma os remédios junto, e eu acho que está no nosso papel, daí é reforçar e orientar...

Tolerar conhecimentos populares sem compreender as concepções subjacentes do usuário, não permite um atendimento integral. Ao contrário, continua o modelo tradicional de assistência para o qual o profissional da saúde é o detentor do conhecimento, e o saber trazido pelo paciente não é significativo para a terapêutica. As terapias alternativas tem apenas um efeito placebo segundo a fala do médico: [...] Tem efeito placebo bom muitas vezes... Está se hidratando, está tomando um chá. Chá é ansiolítico... Acho que não dá para bater de frente com essa coisa cultural, popular, mas tem que negociar...

Além da sua eficácia material, as práticas de cura corroboradas por crenças, representações e valores, compartilhados entre o paciente e o terapeuta, trazem efeitos mágicos. Entretanto, quando as terapêuticas não científicas demonstram eficácia, esta é taxada, pejorativamente, de efeito placebo, pois repercute diversamente ao esperado pelo conhecimento científico ${ }^{12}$.

A tolerância significa para o médico uma negociação: Eu não posso deixar alguém que está com uma patologia que eu sei que não vai curar, e pelo menos vão tentar negociar isto. [...]? O que a gente pode oferecer? Então tem que negociar, nem 8 nem 80 , tem que ter um bom senso.

A supervalorização do conhecimento científico fortalece as barreiras que impedem 'trocas' entre o universo reificado e o consensual. A não promoção de um processo de transferência de conhecimentos e práticas silencia possíveis reivindicações de singularidades, disponibilizando uma assistência à saúde, desinvestida de preocupações com a cultura da população. Contudo, a saúde deve ser entendida não só como a ausência de doença, mas um aproveitamento mais eficiente de todos os recursos com que conta cada grupo para mobilizar sua própria atividade na procura de melhores condições de vida, tanto no campo material como no cultural, no social e no psicológico ${ }^{13}$.

Uma tentativa de transferência aparece na fala de uma enfermeira: Eu invento uma história, tem funcionado, invento que antigamente elas foram tomar banho no rio que era gelado, e por isso a pessoa que já tinha um problema mental... Lavava a cabeça de cabeça para baixo... Aí acaba que elas se convencem, é complicado, você tem que respeitar, tu não pode dar risada, Deus o livre, tem que ficar sério.

A conversa entre o profissional e o usuário não serve para preencher o vazio da ignorância com conhecimento científico, mas compreender os pensamentos e as condutas previamente existentes no indivíduo. Num contexto em que não existem atores privilegiados na produção de saúde, um programa participativo implica que todos atuem por igual com papéis diferenciados, tentando superar a assimetria da relação, significando que não se trata de que um manda e o outro obedece ou um ensina e o outro simplesmente aplica ${ }^{2}$.

Um processo participativo resulta do confronto de perspectivas e prioridades, diferentes e legítimas, tanto dos agentes de saúde quanto dos usuários. Por isso é importante conhecer os saberes e os costumes da comunidade, como base para um processo de educação em saúde que valoriza a subjetividade do usuário e a transferência de conhecimentos. Isso implica práticas respeitosas e solidárias ${ }^{2}$.

A prática de uma enfermeira expressa essa valorização do sujeito como base para a transferência de informações: Se tu consegue fazer um bom vinculo, por mais que tenha essa influência da tradição eles acabam ouvindo e fazendo como aprenderam. Eu percebo isso no grupo de gestantes [...] sempre friso: 'olha, não é que tua mãe está errada, é que ela aprendeu dessa forma, as coisas evoluiram, as pessoas foram estudando e viram que isso não funciona mais'...

A medicalização da vida é mais um elemento da dominação instrumental do processo de industrialização, que incapacita as pessoas a en- 
contrar soluções por si mesmas. Elas são condicionadas na obtenção das coisas que necessitam ao invés de consegui-las por iniciativa própria. Perdem a autonomia, porque são sempre mais guiadas e dependentes de outros. A cura deixa de ser tarefa do doente, passando a ser um encargo de quem toma conta do paciente. Da mesma forma como a única educação aceita e legítima é aquela dada pela escola, desconsiderando todos os conhecimentos adquiridos por outros meios, o tratamento da saúde também passa a ser exercício exclusivo da prática médica ${ }^{14}$.

Um novo tipo de relação é necessário, fugindo do padrão tradicional onde um é o sujeito e o outro o objeto de intervenção para melhoria da saúde. Trata-se de um processo que perpassa a relação de assistência, equiparando os dois sujeitos da relação a partir de novos olhares do campo profissional: a construção efetiva do cuidado em consonância com a autonomia do usuário ${ }^{15}$. A nova relação acontece entre profissional e usuário, produtores de saúde ${ }^{1}$.

\section{Integração entre os conhecimentos}

A transferência entre o universo científico e popular é necessária para que haja confiança e credibilidade no atendimento, fato que ficou explícito nas falas do grupo analisado. Poucos profissionais acreditam nestas 'trocas' como forma de atendimento integral, mas sabe-se que tal interface mostra-se necessária para o sucesso do vínculo entre usuário e profissional na construção do processo saúde/doença ${ }^{4}$.

O universo reificado, criado pela ciência, produz um distanciamento e estranhamento em relação à experiência cotidiana, tornando-a não familiar. O universo consensual, ao contrário, é o lar cultural. O que acontece é confirmado pelas crenças e interpretações adquiridas, corroborando a tradição. A finalidade de todas as representações é tornar familiar algo não familiar, ou a própria não familiaridade de um conhecimento ${ }^{7}$.

Tendo presente a importância de encontrar uma ancoragem em algo já conhecido para integrar o dado novo, apenas uma minoria dos profissionais da ESF valoriza os conhecimentos trazidos pelos usuários, como base para a compreensão do que é proposto e como complementares à terapia convencional, desverticalizando os saberes. Essa valorização aparece na fala de uma técnica em enfermagem: [...] Eu acredito muito em chás, o povo conhece muita coisa [...]. Faz dois anos que eu tive um grupo muito forte. Fizeram sabão, pomadas, xaropes, e assim... Foi tão interessante que as doutoras vinham pedir [...] coisa que veio delas e que voltou, que converteu pra população.

Conhecimentos originados na cultura popular complementam o saber científico, vislumbrando-se um processo de ancoragem e de transferência do universo consensual para o universo reificado e salientando sua relevância para a rotina da ESF. Essa complementação demonstra a possibilidade de integrar diferentes conhecimentos na prática, promovendo uma assistência resolutiva e comprometida com a realidade da população assistida e traduzindo o verdadeiro sentido da integralidade ${ }^{6}$.

Profissionais e usuários apresentam práticas de saúde diversas que precisam expandir-se para que ocorra a comunicação. Esta deve se dar de forma bidirecional, gerando um compromisso de transformação dos saberes de cada um. Se os dois lados detêm conhecimentos, a saúde se dá em um processo de diálogo, no qual, ambos se comprometem a transformar-se $\mathrm{e}^{2}$.

Assim, os percursos de saúde estão em constante transformação, pois todos se responsabilizam pelo processo, sendo coatores, participando em graus diversos na produção da saúde. Tal resultado deve ser discutido, revisto e pactuado por todos.

A proposta da clínica ampliada na atenção básica reconhece que os sujeitos estão imersos em 'teias' de forças que os constituem, levando a valorizar práticas clínicas 'misturadas' que integram elementos socioculturais e se distanciam de purismos das racionalidades médicas, dos modelos teóricos exclusivistas e das intervenções isoladas. A construção compartilhada de conhecimento na clínica ampliada considera que a experiência cotidiana dos indivíduos e o poder de intervenção das relações sociais influenciam sobremaneira a qualidade de vida das pessoas e das comunidades ${ }^{16}$.

Neste sentido, só será possível conhecer integralmente o usuário quando o profissional reconhecer a cultura do outro, transcendendo seus conhecimentos técnico-científicos, permeando-se de outros conceitos e visões, tornando-se participe de um contexto onde não há preconceitos nem pré-conceitos estabelecidos ${ }^{5}$. Isso aparece na afirmação da enfermeira: [...] O trabalhador de saúde tem que tentar pelo menos ser desprovido de preconceitos, isso cada vez mais [...] essas pessoas encaram a vida de forma diferente, de maneira diferente de tu... Tem que aprender a lidar, a trabalhar isso.

Briceño-Léon diz que somente conhecendo o indivíduo e suas circunstâncias são possíveis ações eficientes e permanentes em saúde ${ }^{2}$. Por isso a im- 
portância de incluir conhecimentos de significância para os usuários na construção de novas práticas.

Estes, quando buscam atendimento, estão buscando atenção, respeito e cuidado para seus anseios e sofrimentos. Esse foco muitas vezes é desviado, porque o profissional se centra na doença e não nas necessidades do usuário a ser tratado e entendido. A consulta constitui o laço que guia a relação profissional-usuário, primordial para que ambos estejam centrados e abertos a uma relação de confiança.

O ritual da consulta reveste-se de grande importância simbólica, pois as crenças, tanto do usuário como do profissional, tornam-se aliados da relação. Para produzir saúde, a eficácia simbólica é essencial como agente terapêutico, garantindo a adesão dos usuários ao tratamento proposto, reduzindo efeitos colaterais e permitindo doses menores de determinadas drogas. Quando este é assistido por um profissional hostil e/ou indiferente aos seus valores, o tratamento pode ser abandonado ou até acarretar respostas $\operatorname{adversas}^{12}$.

Diante de diferentes visões no momento da consulta ou do contato com o serviço de saúde, a saída possível para que o processo clínico tenha sucesso, é uma 'negociação entre as partes', cada um usando os seus argumentos para que se chegue a um consenso possível. É preciso chegar a uma pactuação, ao menos temporária, entre o agente da cura e o usuário ${ }^{17}$.

O profissional é convidado a ter em consideração as crenças populares com o objetivo de desmitificar tabus, conseguindo a sustentabilidade e a eficácia de suas ações e promovendo a saúde da população ${ }^{18}$. O usuário é visto não mais como um sujeito passivo, como um 'paciente', mas alguém que interage e busca a reconstrução de sua saúde. O profissional é um aliado nessa busca, alguém com um saber diferente, porém não melhor e sim complementar para essa relação.

A transferência e a interação entre os universos, consensual e reificado, ainda são fatos isolados dentro da ESF. No entanto, alguns profissionais acreditam que a negociação e o aprendizado são os caminhos para uma estratégia que visa a autonomia e a promoção de saúde. A construção de conhecimento implica num intercâmbio mútuo entre sujeitos com saberes diferentes, porém não hierarquizados ${ }^{19}$.

Esse intercâmbio aparece na fala de um médico, quando interpreta a não maleficência e a beneficência como autonomia: Tem que tentar preservar a autonomia do paciente, mas pensando na não maleficência. Tem também que trabalhar como informar mais adequadamente para aqueles que estão em risco... Ter o princípio da beneficência é eticamente tu introduzir ele no caminho dele. Tem que trabalhar o discurso do sujeito que é o paciente, ele tem uma cultura, uma representação social...

A integração entre os universos acontece na medida em que uma relação é construída, no momento em que vínculos são constituídos e, por consequência, acolhimentos são efetuados. Só é possível entender, compreender e buscar melhorias naquilo que se conhece, quando os profissionais interagirem e efetivamente fazerem parte do universo de seus pacientes, e na medida em que se deixarem envolver por eles. É no diálogo entre os universos que a integração acontece. Por estarem na mesma busca e por caminharem lado a lado na procura por novas interações, eles se complementam.

As representações sociais e o ambiente cultural são os mediadores dessa transferência. Franco e Merhy apontam que: Os diversos saberes articulam-se num emaranhado de saberes que, em relações intercessoras com os usuários, produzem o cuidado ${ }^{1}$.

As palavras de um médico apontam para essa difícil articulação: Porque essa pessoa age de tal forma e não de outra? Porque ela tem seus princípios, suas crenças, seus valores, que não são os meus, nem do médico e nem da técnica em enfermagem. Tem que entender isso, não é fácil. Até porque você também tem que mudar os teus conceitos, e a gente sabe que não é fácil.

Fica evidenciada a preocupação do profissional em levar em consideração a realidade de quem busca ser assistido e cuidado. Ele compreende a necessidade de adequar seu conhecimento ao universo biopsicossocial do usuário para alcançar resultados satisfatórios. Nessa perspectiva surge a preocupação com a autonomia do sujeito, centrando-se naquilo que o outro busca e quer para a sua vida e adaptando-se ao que faz sentido para ele. Não há como falar em integralidade sem que se perceba a realidade daquele que se quer atender em suas necessidades, deixando-se envolver e envolvendo o outro na teia das relações ${ }^{9}$.

As relações interpessoais nos serviços de saúde devem ser cautelosas, para não reproduzirem dominação, mas criar formas solidárias e mais democráticas de produzir coletivamente a saúde e a qualidade de vida. Alguns dos profissionais pesquisados atendem a este perfil, considerando a totalidade do usuário e auxiliando-o na busca de alternativas para seu processo de saúde/doença de forma mais integral ${ }^{20}$. 
Esse perfil aparece na seguinte reflexão de um médico: Tratamento integral é além de você ver o paciente como um todo, no ambiente que ele está inserido, com sua cultura e suas crenças. É tentar trabalhar e trata-lo de acordo com essas crenças, respeitando isso... É você trabalhar em conjunto de uma forma integral com os outros niveis de atendimento.

Cuidar da saúde de uma comunidade exige um perfil profissional que amplie as bases conceituais, englobando as ciências sociais nas ciências da saúde. Isso não as torna menos 'científicas', mas, as aproxima com maior lucidez dos contornos reais dos fenômenos que pretendem abarcar ${ }^{21}$.

A terapêutica deve envolver as várias dimensões da 'doença' - emocionais, sociais, comportamentais e religiosas, exigindo que o tratamento deva ser ampliado ${ }^{20}$. O atendimento integral somente ocorrerá quando o profissional combinar as várias instâncias que constituem o universo popular. Dessa forma, as práticas em saúde se entrelaçam em redes que interagem e influenciam-se mutuamente, potencializando a busca de soluções às problemáticas experenciadas ${ }^{19}$.

A complexidade da saúde exige respostas que ultrapassem a assepsia técnica, incentivando a interação com o universo popular e buscando alternativas de solução para as necessidades apresentadas ${ }^{19}$. Essa dimensão supõe profissionais ativos e interativos em relação à dinâmica popular local para que a construção da saúde reflita o real perfil e necessidade da comunidade assistida.

\section{Conclusão}

A teoria das representações sociais de Moscovici $^{7}$ possibilita identificar e interpretar a dicotomia entre conhecimento popular e científico, auxiliando na compreensão das práticas hegemônicas que não consideram os saberes baseados na cultura popular. Também expõe o abismo entre tais saberes, apontando a necessidade de uma ancoragem como forma de tornar algo antes avaliado como sem sentido, em uma prática compreendida e aceita pela população.

O diálogo entre os dois universos, o consensual do saber popular e o reificado do conhecimento científico, revela-se como uma prática indispensável para a consecução dos objetivos da ESF, já que se pretende delinear um novo para- digma, trazendo os processos de saúde para o seio da comunidade. A estratégia, ao pautar suas ações em um atendimento integral, valorizando os diferentes contextos e a realidade de cada sujeito assistido, deve abandonar práticas baseadas na sobreposição do conhecimento técnicocientífico, resgatando e/ou constituindo ações de saúde em interação com a comunidade.

A ESF, alicerçada em ações desverticalizadas que priorizam dinâmicas biopsicossociais, depende, em grande parte, do modo como os profissionais se posicionam frente às percepções e compreensões de saúde e doença da comunidade atendida. Ao mesmo tempo, mostra como a formação de vínculo, o ambiente acolhedor e a busca de um cuidado atento às subjetividades singulares de cada usuário são elementos desencadeantes do sucesso da relação equipe/usuário.

Pautada na visão ampliada de clínica, a ESF compreende o indivíduo em sua totalidade e em sua rede coletiva, exigindo a necessária interlocução entre usuário e profissional sobre os percursos terapêuticos. De acordo com a pesquisa, apenas uma minoria valoriza e utiliza os conhecimentos populares como complementares aos conhecimentos científicos, acreditando que o tratamento, a promoção e a prevenção de saúde devem ser construídos a partir das concepções culturais da comunidade atendida. Porém, essa minoria composta por profissionais engajados na proposta, detém o perfil adequado para lidar com a diversidade de sujeitos, tratando-os a partir de seus universos singulares e próprios.

A valorização das crenças e das práticas do usuário viabiliza a percepção corresponsável do seu processo terapêutico e do próprio sistema que o sustenta. Dessa forma, tanto os serviços como os profissionais são convidados à comunicação com seus usuários, identificando por trás de cada pessoa uma representação social, base para a ancoragem de novos conhecimentos que podem propiciar maior qualidade de vida e saúde integral. Trata-se de entender e considerar as formas alternativas de cura a partir do seu contexto cultural como complementares e como base simbólica da eficácia das terapias convencionais da ciência, sempre em benefício dos usuários, já que do encontro entre os diferentes saberes acontece a produção da saúde na e da comunidade. 


\section{Colaboradores}

JR Junges, R Barbiani, NA Soares, RBP Fernandes e MS Lima participaram da concepção, da escrita e da correção do artigo.

\section{Referências}

1. Franco TB, Merhy EE. Programa Saúde da Família (PSF): Contradições de um programa destinado à mudança do modelo tecnoassistencial. In: Merhy EE, organizador. O trabalho em saúde: olhando e experenciando o SUS no cotidiano. São Paulo: Editora Hucitec; 2003.

2. Briceño-León R. Siete tesis sobre la educación sanitaria para la participación comunitaria. Cad Saude Publica 1996; 12:07-17.

3. Bardin L. Análise de Conteúdo. Lisboa: Edições 70; 1979.

4. Nunes MO, Trad LB, Almeida BA, Homem CR, Melo MCI. O agente comunitário de saúde: construção da identidade desse personagem híbrido e polifônico. Cad Saude Publica 2002; 18(6):1639-1646.

5. Caprara A, Rodrigues J. A relação assimétrica médico-paciente: repensando o vínculo terapêutico. Cien Saude Colet 2004; 9(1):139-146.

6. Leite SN, Vasconcellos MPC. Negociando fronteiras entre culturas, doenças e tratamento no cotidiano familiar. História, Ciências, Saúde - Manguinhos 2006; 13(1):113-128.

7. Moscovici S. Representações sociais: investigações em psicologia social. Petrópolis: Editora Vozes; 2003.

8. Minayo MCS. O desafio do conhecimento - Pesquisa qualitativa em saúde. São Paulo: Hucitec, Rio de Janeiro: Abrasco; 2006.

9. Pinheiro R, Luz MT. Práticas Eficazes x Modelos Ideais: ação e pensamento na construção da integralidade. In: Pinheiro R, Mattos R, organizadores. A construção da integralidade: cotidiano, saberes e práticas em saúde. Rio de janeiro: Abrasco - UERJ; 2003.

10. Abreu W. Saúde, doença e diversidade cultural. Lisboa: Instituto Piaget; 2003.

11. Nardi H. Subjetividade, trabalho e ética. In: Nardi H. Ética, trabalho e subjetividade. Porto Alegre: Editora da UFRGS; 2006.

12. Camargo Júnior KR. Biomedicina, Saber \& Ciência: uma abordagem crítica. São Paulo: Hucitec; 2003.
13. Bleger J. Temas de Psicologia. $4^{a}$ ed. São Paulo: Martins Fontes; 1989.

14. Illich I. Nemesis da medicina. A expropriação da saúde. Rio de Janeiro: Nova Fronteira; 1975.

15. Caprara A, Franco ALS. A relação paciente-médico: para uma humanização da prática médica. Cad Saude Publica 1999; 15(3):647-654.

16. Cunha GT. A construção da clínica ampliada na atenção básica. São Paulo: Hucitec; 2005.

17. Oliveira FA. Antropologia nos serviços de saúde: integralidade, cultura e comunicação. Interface Comunic, saúde, educ 2002; 6(10):63-74.

18. Oliveira ATSA, Moreira CT. Crendices e práticas populares: influência na assistência de enfermagem prestada à criança no Programa Saúde da Família. Rev. Bras. Psicologia Social 2002; 19(1):11-18.

19. Carvalho MAP, Acioli S, Stotz EN. O processo de construção compartilhada do conhecimento - uma experiência de investigação científica do ponto de vista popular. In: Vasconcelos EM, organizador. A saúde nas palavras e nos gestos - reflexões da rede educação popular e saúde. 2a ed. São Paulo: Hucitec; 2001.

20. Helman C. Cultura, saúde e doença. $4^{\text {a }}$ Ed. Porto Alegre: Artes Médicas; 2003.

21. Minayo MCS. Abordagem antropológica para avaliação de políticas sociais. Rev Saude Publica 1991; 25(3):233-238.

Artigo apresentado em 30/05/2008

Aprovado em 16/02/2009

Versão final apresentada em 23/02/2009 
